\title{
Ethics guidelines strengthened but reach remains limited
}

$\mathrm{C}$ anada's granting councils have issued an updated draft of ethics guidelines governing human research, including expanded sections about aboriginal and qualitative research, as well as bolstered chapters concerning genetic and human-tissue research and clinical trials.

While some researchers are praising the changes as a good response to community concerns and evolving ethical principles, others caution that they do not adequately address emerging governance problems as health research moves from research-based institutions into community settings.

"What is not covered is as important as what is covered - in particular, research conducted in the private sector or in private physicians' offices," says Michael McDonald, who holds the Maurice Young Chair of Applied Ethics at the University of British Columbia.

Adherence to the Draft 2nd Edition of the Tri-Council Policy Statement: Ethical Conduct for Research Involving Humans is required of all researchers who receive funding from the Canadian Institutes of Health Research, the National Sciences and Engineering Research Council, and the Social Sciences and Humanities Re- search Council. In addition, Association of Universities and Colleges of Canada member institutions are bound by the standards under a memorandum of understanding signed with the 3 granting councils. Nongovernmental organizations and federal departments also comply, Derek Jones, an exofficial member of the Interagency Advisory Panel on Research Ethics, which drafted the guidelines, told a December 2008 news conference.

But the Tri-Council policy does not govern private-sector research. Nor does it govern work overseen by private research ethics boards or trials organized by contract research firms.

"The mandate of the committee was to revise the Tri-Council Policy Statement, but there are many outstanding research ethics issues, such as governance, monitoring and oversight," Tim Caulfield, advisory panel member and research director of the Health Law Institute at the University of Alberta, told CMAJ in an email.

The statement, which updates the Tri-Council's 1998 policy, will not be finalized until scheduled community consultations are completed in March. It broadly articulates ethical principles, while hoping to address societal and technological trends. For example, it warns that genetic research, however important to preventing and treating disease, has the potential "to exploit or stigmatize individuals or groups, who may experience discrimination or other harms because of their genetic status." Such work may uncover delicate "nonpaternity" issues or may lead to obligations on individuals to disclose disease predisposition risks to their employers or insurers.

McDonald praises the policy's "new and useful" sections about conflict of interest, which stress the possibility of institutional conflicts, in addition to those individual researchers might have.

But he raises questions about where contract research organizations fall, particularly those hired by the pharmaceutical industry to recruit patients and run trials. "Are they regulated directly under Health Canada rules, or indirectly because they have contracts with pharmaceutical companies? It's an area that is murky."

The new statement incorporates many attitudes that were considered radical 10 years ago, says McDonald, who wrote an influential Law Commission of Canada report on the need for

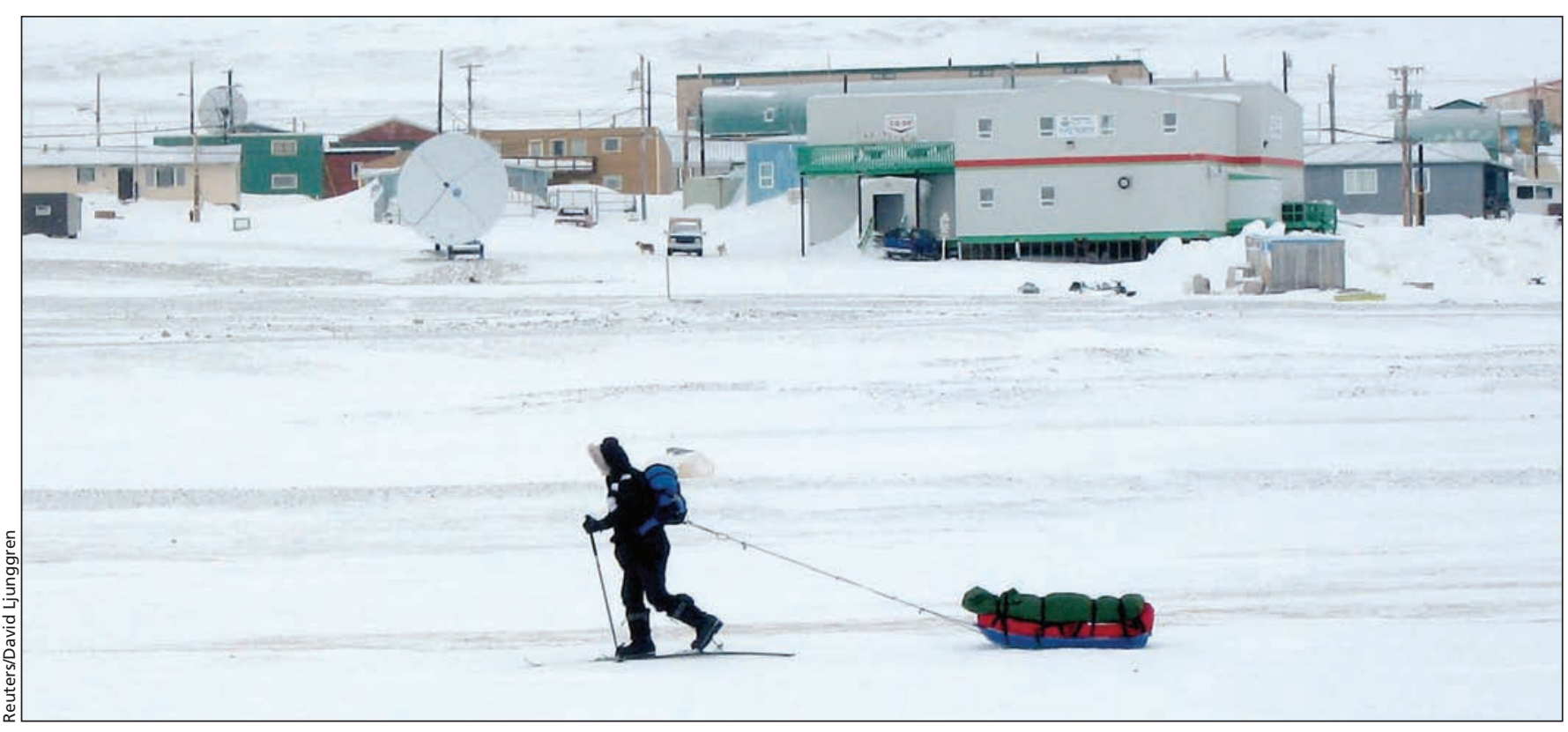

Research involving Aboriginal peoples should not be undertaken without community participation, according to revisions in granting council policy on research involving human subjects. 
stronger protections for human research subjects in 2000. "There's more recognition that research participants aren't just individuals, they are part of families and communities. What's interesting is to see the evolution of thinking around these things."

University of Toronto Professor of Public Health Lorraine Ferris says the guidelines provide much-needed clarification, while being responsive to community concerns.

But Ferris and McDonald raise concerns that the document does not fully address institutional potential conflicts of interest. In the past, clinical trials involving drugs and medical devices usually took place in academic settings, even if a pharmaceutical company was the external sponsor of the trial. The research was then governed by the institution's Research Ethics Board.

Today, the institutions themselves sponsor clinical trials, and that could put them in a potential conflict, say Ferris and McDonald. "There needs to be more clarity around how the institution applies the rules," Ferris says.

In addition, McDonald believes Research Ethics Boards at institutions should not report to the vice-president of research, because that job involves promoting and attracting research and research dollars - to the institution. If a board discovers an ethical problem with research, that finding puts the vice-president into the tense situation of wondering how action regarding the problem will affect his or her ability to attract dollars.

Boards should report to another administrator, McDonald says. "There is a real conflict of roles here."

Susan Zimmerman, executive director of the Secretariat on Research Ethics, which provides administrative support to the advisory panel, says feedback on the proposed changes has thus far been positive. "Obviously whatever the policy statement says, it is just about the conduct of research itself. How we in this country govern research is a separate issue. We have been involved in that dialogue but that is separate from the policy statement itself." — Laura Eggertson, CMAJ

DOI:10.1503/cmaj.090093

\section{Failing grade for public-private partnership hospitals}

$\mathrm{O}$

ntario could have saved hundreds of millions of dollars if the Brampton Civic Hospital had been built and operated publicly rather than under a public-private partnership (P3), Ontario Auditor General Jim McCarter says.

The government could have saved almost $\$ 100$ million on the cost of design, construction and provision of nonclinical services if it had followed traditional procurement methods. Because the government can obtain lower interest rates, another $\$ 200$ million in savings could have accrued had the government, rather than industry, borrowed money for the project, McCarter wrote in his 2008 annual report (www.auditor.on.ca/en/reports_en/en08 1303en08.pdf).

The Brampton Civic Hospital was the first built in Ontario using the P3 funding model, under which the government pays a private consortium to design, build and finance a hospital, and in some cases to provide nonclinical services such as laundry, food and security (CMAJ 2008;179[9]:883-5). Ontario has planned or started construction on more than 30 such healthrelated P3 projects, which have drawn considerable criticism (CMAJ 2008; 179[10]:991-4).

McCarter's report, the most thorough review to date of a P3 hospital done by an auditor general, supports some of the criticism, saying that costs and benefits weren't adequately assessed.

The "value for money" assessment was overestimated by $\$ 634$ million, while the cost of construction using the P3 model nearly doubled. The value of "risk transfer," the estimate of what it will cost the consortium to deliver the project on time, was also overestimated by a wide margin, according to $\mathrm{Mc}$ Carter. Proponents of P3s say risk transfer is one of the major benefits of this funding model.

P3 opponents, such as Natalie Mehra, director of the Ontario Health Coalition, say they've been vindicated by the findings. Paul Moist, Canadian Union of Public Employees national

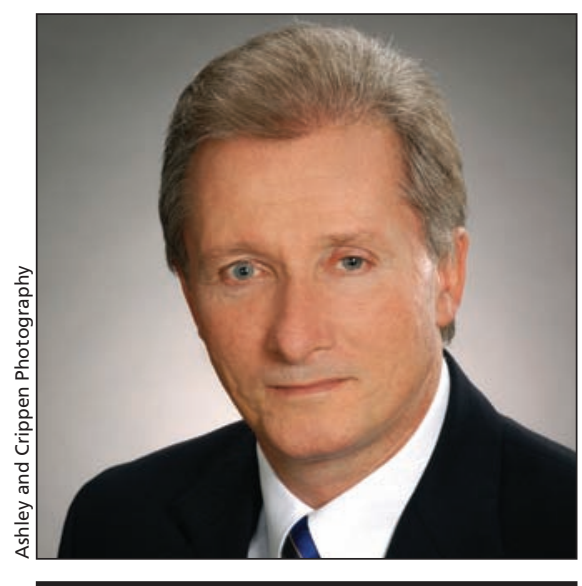

Ontario Auditor General Jim McCarter

president, adds that the report "confirms our worst expectations that this was a boondoggle."

The government agency responsible for overseeing P3 projects says all problems have since been solved, while recommendations for improving transparency, accountability and value-formoney assessments have been adopted.

Infrastructure Ontario Manager of Corporate Relations Doug DeRabbie also says summaries of value-for-money assessments are available on the crown corporation's website, although full reports aren't posted because they contain sensitive material (www.infrastructureontario.ca/en/projects/index.asp).

But these summaries, which are short and have some information blacked out, indicate only a lack of openness and transparency, says Mehra, who says its disingenuous to claim that value-for-money assessments are publicly available. "All they do is compare the bottom lines. That is not a value-for-money audit."

The Ontario Health Coalition is calling for a moratorium on $\mathrm{P} 3 \mathrm{~s}$, pending a public review. The British Columbia chapter of the Canadian Union of Public Employees has renewed calls for the province's auditor general to closer scrutinize P3 projects. "We think it's an equally bad story," Moist says. Erika Gilbert, Ottawa, Ont.

DOI: $10.1503 / \mathrm{cmaj} .090065$ 